\title{
Magnetic resonance imaging is effective for evaluating the therapeutic effect of tolvaptan on total kidney volume in patients with autosomal dominant polycystic kidney disease
}

Shuma Hirashio ${ }^{1,2}$, Shigehiro Doi ${ }^{1}$ and Takao Masaki ${ }^{*}$

\begin{abstract}
Background: Autosomal dominant polycystic kidney disease (ADPKD) is the most common inherited disease among primary diseases in dialysis patients. Tolvaptan is known to improve increases in total kidney volume (TKV) in patients with ADPKD, thereby slowing the progression of kidney dysfunction. However, TKV is not always measured using magnetic resonance imaging (MRI), and the specific effect of tolvaptan has yet to be determined.

Case presentation: We examined six patients (four males and two females) who underwent tolvaptan treatment at the Higashi-Hiroshima Medical Center. TKV was measured by volumetry using magnetic resonance imaging (MRI) at three time points (before, at the time of, and 1 year after the start of tolvaptan treatment). The rates of change in TKV and estimated glomerular filtration rate (eGFR) were also measured before and at the start of treatment, and values at the start of treatment and after treatment were compared. Data were analyzed using Wilcoxon's signed-rank test.

After the start of tolvaptan treatment, the rates of change in TKV were significantly decreased compared with those before treatment (before treatment, $9.2 \mathrm{~mL} / \mathrm{min} / 1.73 \mathrm{~m}^{2} /$ year [range 7.4-10.2]; after treatment, $2.4 \mathrm{~mL} / \mathrm{min} / 1.73 \mathrm{~m}^{2} /$ year [range 0.8-5.9], $P=0.031$ ). The rates of change in eGFR were not significantly different after the start of tolvaptan treatment (before treatment, $9.2 \mathrm{~mL} / \mathrm{min} / 1.73 \mathrm{~m}^{2} /$ year [range $7.4-10.2$ ]; after treatment, $2.4 \mathrm{~mL} / \mathrm{min}$ / $1.73 \mathrm{~m}^{2} /$ year [range $0.8-5.9$ ], $P=0.58$ ).
\end{abstract}

Conclusions: MRI enables accurate evaluation of the initial therapeutic effect of tolvaptan on TKV in Japanese ADPKD patients.

Keywords: Tolvaptan, Estimated glomerular filtration rate (eGFR), Autosomal dominant polycystic kidney disease (ADPKD), Total kidney volume (TKV), Magnetic resonance imaging (MRI)

\footnotetext{
* Correspondence: masakit@hiroshima-u.ac.jp

'Department of Nephrology, Hiroshima University Hospital, 1-2-3 Kasumi,

Minami-ku, Hiroshima Zip 7348551, Japan

Full list of author information is available at the end of the article
}

(c) The Author(s). 2018 Open Access This article is distributed under the terms of the Creative Commons Attribution 4.0 International License (http://creativecommons.org/licenses/by/4.0/), which permits unrestricted use, distribution, and reproduction in any medium, provided you give appropriate credit to the original author(s) and the source, provide a link to the Creative Commons license, and indicate if changes were made. The Creative Commons Public Domain Dedication waiver (http://creativecommons.org/publicdomain/zero/1.0/) applies to the data made available in this article, unless otherwise stated. 


\section{Background}

Autosomal dominant polycystic kidney disease (ADPKD) is a hereditary disease characterized by the progressive growth of multiple cysts in both kidneys. Currently, the number of ADPKD patients in Japan is estimated to be 31,000 , accounting for roughly $3-5 \%$ of all dialysis patients [1]. As the most important clinical feature in ADPKD, increases over time in the number and size of renal cysts contribute to both kidney enlargement and the promotion of kidney dysfunction, eventually leading to the requirement for renal replacement therapy [2]. Importantly, Grantham et al. reported that kidney size predicts the prognosis of renal failure in ADPKD patients [3]. Therefore, precise measurement of total kidney volume (TKV) should be established for evaluation of the progression of ADPKD.

In 2003, Gattone et al. reported that administration of a vasopressin V2 receptor antagonist inhibited the generation and enlargement of cysts in animal models of polycystic kidney disease [4]. Since 2014, tolvaptan, a member of the family of vasopressin V2 receptor antagonists, has been approved for the treatment of ADPKD in Japan. During a phase III international collaborative study (TEMPO $3: 4$ study) [5], the rate of increase in TKV was $2.8 \%$ per year in the group administered tolvaptan, whereas it was $5.5 \%$ per year in the group treated with placebo. However, evaluation of increases in TKV was performed by ultrasound sonography (US) or computed tomography (CT).
Therefore, the actual effect of tolvaptan on increases in kidney volume remains inconclusive.

While US, CT, and magnetic resonance imaging (MRI) have each been used to quantify TKV in ADPKD patients, MRI is considered the most accurate method for measuring TKV [6, 7]. Although a recent study reported that, in addition to age, TKV predicts the risk of decline in glomerular filtration rate [8], there are few reports demonstrating the therapeutic effect of tolvaptan on TKV evaluated by MRI. In this study, we performed MRI to investigate the actual effect of tolvaptan in patients with ADPKD.

Herein, we administered tolvaptan to six ADPKD patients and followed them for 1 year. We performed MRI to investigate the effect of tolvaptan on TKV and estimated glomerular filtration rate (eGFR) before and after tolvaptan treatment.

\section{Case presentation}

We analyzed six patients (four males and two females) who underwent tolvaptan treatment between October 2014 and May 2015. Patients underwent kidney function tests and MRI at three time points (before, at the time of, and 1 year after the start of tolvaptan treatment). We also investigated changes in these parameters before and after treatment. TKV was measured by volumetry using a PHILIPS Achieva 1.5 tesla MRI system. Briefly, kidneys were scanned using a balanced fast field echo sequence,
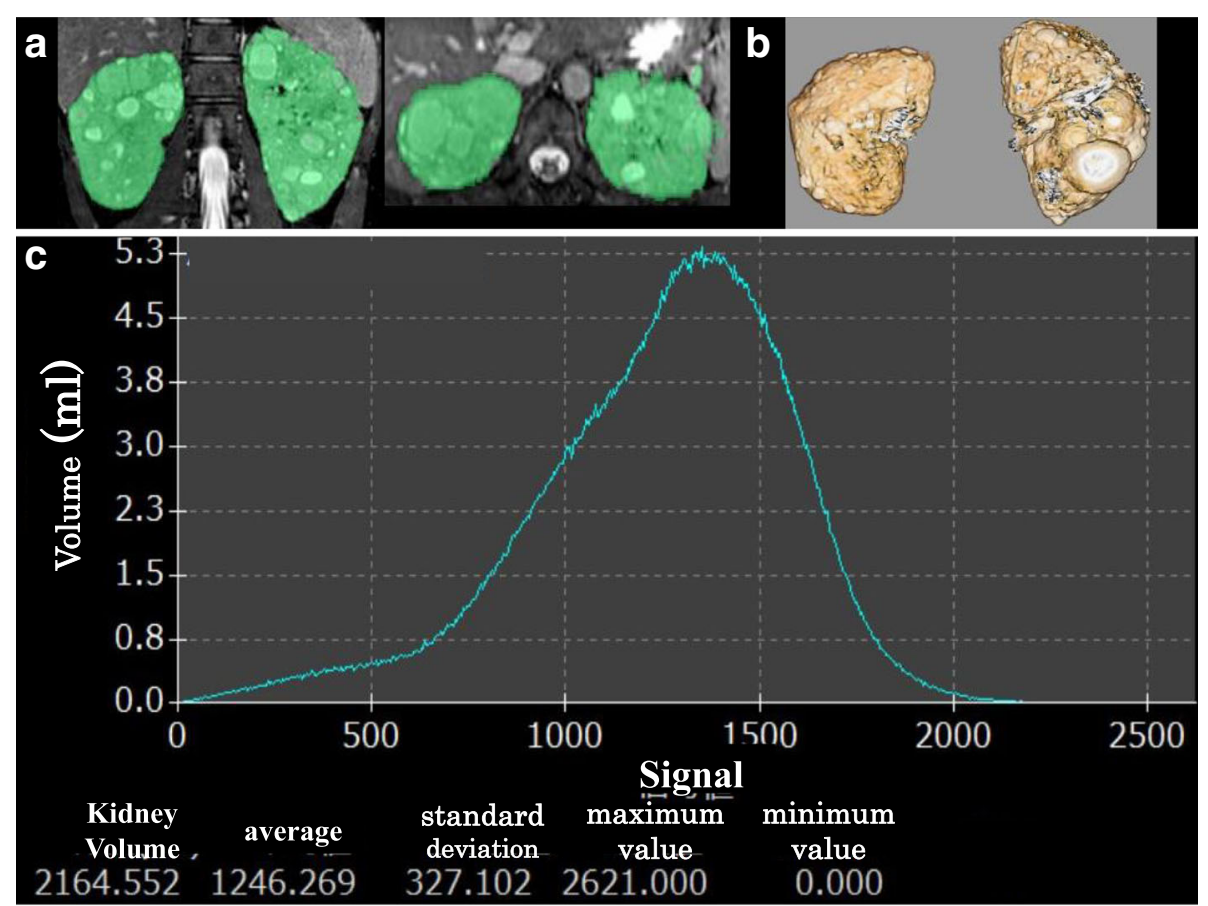

Fig. 1 Measurement of total kidney volume. a Traced kidney image by magnetic resonance imaging. $\mathbf{b}$ Kidney image assembled in three-dimensions. c Integral graph 
Table 1 Baseline clinical characteristics of patients before treatment

\begin{tabular}{|c|c|c|c|c|c|c|c|}
\hline & Age (year) & Sex & Serum $\mathrm{Cr}(\mathrm{mg} / \mathrm{dL})$ & eGFR $\left(\mathrm{mL} / \mathrm{min} / 1.73 \mathrm{~m}^{2}\right)$ & CKD stage & $\mathrm{TKV}(\mathrm{ml})$ & Cerebral aneurysm \\
\hline Case 1 & 37 & Male & 0.76 & 92.9 & G1A1 & 788 & $(-)$ \\
\hline Case2 & 51 & Female & 0.89 & 52.7 & G3aA1 & 1070 & $(-)$ \\
\hline Case3 & 55 & Male & 1.29 & 46.5 & G3aA1 & 1756 & $(-)$ \\
\hline Case4 & 38 & Male & 1.67 & 39.0 & G3bA1 & 4060 & $(+)$ \\
\hline Case5 & 54 & Male & 1.56 & 38.0 & $\mathrm{G} 3 \mathrm{bA} 1$ & 2165 & $(-)$ \\
\hline Case6 & 52 & Female & 1.80 & 24.3 & G4A2 & 1313 & $(-)$ \\
\hline
\end{tabular}

$C r$, creatinine; eGFR, estimated glomerular filtration rate; $C K D$, chronic kidney disease; $T K V$, total kidney volume

and the corresponding images were assembled into threedimensions. Next, we used an image analysis system (VINCENT, FUJI Film Co, Tokyo, Japan), and kidneys were traced in horizontal, coronal, and sagittal sectional views. Subsequently, traced kidney images were analyzed graphically, and the dimensions were integrated. Finally, we converted the dimensions into TKV (Fig. 1).

All six patients were confirmed to have a family history of ADPKD. We also recorded the eGFR of patients at three time points (at baseline, just before treatment, and after 1 year of treatment). The eGFR was calculated according to the formula for estimating kidney function from the Japanese Society of Nephrology [males: eGFR $\left(\mathrm{mL} / \mathrm{min} / 1.73 \mathrm{~m}^{2}\right)=194 \times \mathrm{Cr}-1.094 \times$ Age -0.28 , female: eGFR $\left(\mathrm{mL} / \mathrm{min} / 1.73 \mathrm{~m}^{2}\right)=194 \times \mathrm{Cr}-1.094 \times$ Age $-0.28 \times$ 0.739] [9]. We calculated the annual rate of decline of eGFR using the following formula \{(value of eGFR before treatment)-(value of eGFR at the start of treatment) $\} /($ value of eGFR at the start of treatment $) \times 12$ / observation period (months) $\times 100$, or $\{$ (value of eGFR after treatment) - (value of eGFR before treatment)\}/(value of eGFR before treatment) $\times 12$ / observation period (months) $\times 100$.

\section{Statistical analysis}

Statistical analyses were performed using Wilcoxon's signed-rank test. All analyses were performed using
SPSS software package version 23.0 , and $P<0.05$ was considered statistically significant.

\section{Results}

Table 1 shows the baseline clinical characteristics of patients. At the time of tolvaptan treatment, patients were 37-55 years old (median, 51.5 years), TKV was 788-4060 mL (median, $1535 \mathrm{~mL}$ ), serum creatinine level was $0.76-1.80 \mathrm{mg} / \mathrm{dL}$ (median, $1.43 \mathrm{mg} / \mathrm{dL}$ ), and the eGFR was 24.1-92.9 mL/min/1.73 $\mathrm{m}^{2}$ (median, $44.7 \mathrm{~mL} /$ $\min / 1.73 \mathrm{~m}^{2}$ ). An unruptured cerebral aneurysm was observed in one patient (case 4).

As shown in Table 2, each dose of tolvaptan is presented on the CKD heat map [10]. Cases 1 and 4 were administered $120 \mathrm{mg} /$ day, while cases $2,3,5$, and 6 were administered $90 \mathrm{mg} /$ day. Compared with previous reports [5], our patients were administered relatively large doses of tolvaptan, regardless of the degree of renal function impairment.

Figure 2 shows the changes in eGFR before and after treatment with tolvaptan. Regarding changes in eGFR after treatment, two patients showed no changes, three showed improvement, and one showed a decline. Overall, tolvaptan treatment did not result in significant changes in eGFR (before treatment, $9.2 \mathrm{~mL} / \mathrm{min} / 1.73 \mathrm{~m}^{2} /$ year [range 7.4-10.2]; after treatment, $2.4 \mathrm{~mL} / \mathrm{min} / 1.73 \mathrm{~m}^{2}$ / year [range $0.8-5.9$ ], $P=0.58$ ) (Fig. 2). Furthermore, the

Table 2 Doses of tolvaptan administered

\begin{tabular}{llll}
\hline Protein uria & & $<0.15 \mathrm{~g} / \mathrm{gCr}$ & $0.15-0.49 \mathrm{~g} / \mathrm{gCr}$ \\
\cline { 1 - 2 } CKD stage & $\geqq 90$ & 120 (case 1) \\
\hline GFR $\left(\mathrm{mL} / \mathrm{min} / 1.73 \mathrm{~m}^{2}\right)$ & $60 \sim 89$ & \\
& $45 \sim 59$ & $90 / 90$ (case 2 and 3) \\
& $30 \sim 44$ & $120 / 90$ (case 4 and 5) & \\
& $15 \sim 29$ & & 90 (case 6) \\
& $<15$ & &
\end{tabular}




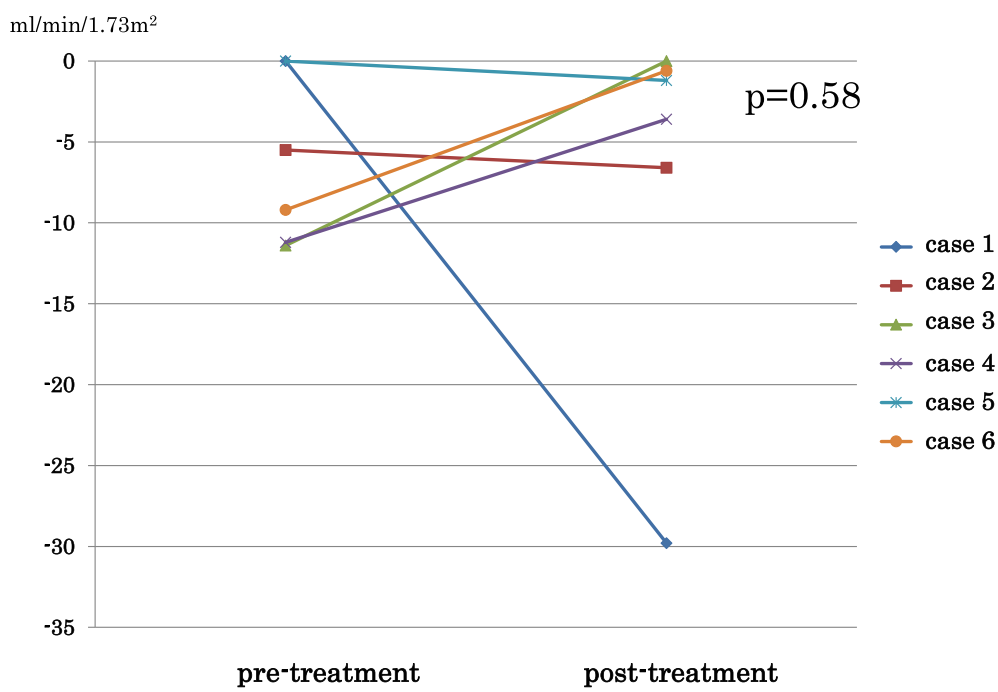

Fig. 2 Rates of change of estimated glomerular filtration rate before and after treatment with tolvaptan. The analysis was performed with Wilcoxon's signed-rank test

rate of increase in TKV was significantly lower after treatment compared with before treatment (before treatment, 14.5\%/year [range 11.3-22.4]; after treatment, 1. $3 \% /$ year [range 0.4-5.7], $P=0.031$ ) (Fig. 3).

Patients were enforced to consume sufficient volumes of water. However, there were no changes in patient weight or blood pressure after treatment compared with values before treatment. Any of the patients were taking antihypertensive drugs prior to the study. However, it was not necessary to modify the use of antihypertensive drugs during treatment with tolvaptan.

\section{Discussion}

In this study, we showed that MRI accurately assesses the therapeutic effect of tolvaptan on TKV in Japanese
ADPKD patients. Of note was that the beneficial effect was observed in cases with severe kidney enlargement and advanced kidney dysfunction. In the clinical setting, US cannot depict three-dimensional outlines of a whole kidney, and CT does not readily distinguish renal cysts from hepatic cysts. However, a previous study reported MRI as a reliable method for measuring TKV $[6,7]$, despite a lack of evidence for evaluation of TKV in ADPKD patients. Our results demonstrated the actual effect of tolvaptan on TKV in Japanese ADPKD patients.

The six patients had a family history of end-stage kidney disease, suggesting they had PKD1 gene mutations that resulted in rapid disease progression [11]. In ADPKD patients with PKD1 gene mutations, TKV is known to increase drastically with age, and kidney

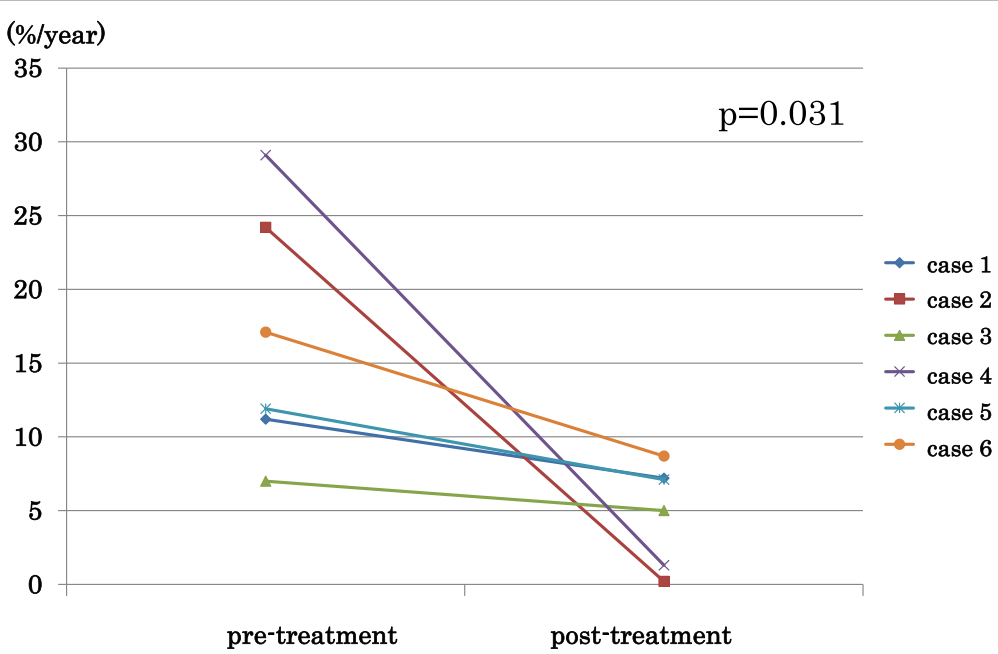

Fig. 3 Rates of change of total kidney volume before and after treatment with tolvaptan. The analysis was performed with Wilcoxon's signed-rank test 
enlargement contributes directly to the progression of kidney dysfunction [11]. In the clinical setting, increased TKV is also used to predict the decline in eGFR in ADPKD patients [8]. In this study, tolvaptan inhibited the annual rate of increase in kidney volume, suggesting that tolvaptan is effective, even in Japanese ADPKD patients considered to have poor renal prognosis.

Although the rate of increase in TKV was suppressed in the six patients, the rate of decline of eGFR did not improve with treatment. In the TEMPO 3:4 study, the mean rate of change in eGFR was reported to be $-2.72 \mathrm{~mL} /$ $\mathrm{min} / 1.73 \mathrm{~m}^{2} /$ year in the tolvaptan group and $-3.70 \mathrm{~mL} /$ $\mathrm{min} / 1.73 \mathrm{~m}^{2} /$ year in the placebo group $[5,12,13]$. However, there was no statistical difference in eGFR at 12 months between the two groups. Notably, an increase in TKV is known to precede the progression to kidney dysfunction [14], and here we showed that tolvaptan inhibits the increase in TKV. The therapeutic effect of tolvaptan on renal function may have been observable after 1 year in patients with ADPKD.

ADPKD is a well-established systemic disease, and tolvaptan has been shown to suppress fibrosis in various rodent model of fibrosis, such as of the heart, liver, and kidney. In contrast, a previous study reported that tolvaptan treatment decreased the size of cysts in patients but did not decrease substantial degrees of cystic wall thickening and interstitial fibrosis [15]. In case 6, eGFR was $24.3 \mathrm{~mL} / \mathrm{min} / 1.73 \mathrm{~m}^{2}$ at the start of treatment despite a relatively small TKV. Because beneficial effects are not expected in patients with advanced kidney dysfunction, the indication of tolvaptan should be determined cautiously in cases with advanced kidney dysfunction and lower kidney size.

Another report indicated that administration of tolvaptan induces tubuloglomerular feedback independently of the reduction in cyst volume, leading to a transient and reversible decrease in eGFR [16]. Notably, the degree of the initial decrease in eGFR following tolvaptan treatment in patients with mild kidney dysfunction was more drastic than in those with advanced kidney dysfunction. In this study, tolvaptan-induced eGFR reduction was most evident in case 1. Given that inhibition of glomerular hyperfiltration is considered a long-term renoprotective effect, tolvaptan may be more effective in patients with mild kidney dysfunction than those with advanced kidney dysfunction.

\section{Conclusions}

In conclusion, MRI accurately demonstrates that tolvap$\tan$ treatment improves increases in TKV in patients with ADPKD.

\section{Acknowledgements}

We thank Richard Robins, PhD, from Edanz Group (www.edanzediting.com/ac) for editing a draft of this manuscript.

\section{Availability of data and materials}

The datasets used and/or analyzed during this study are available from the corresponding author upon reasonable request.

\section{Authors' contributions}

$\mathrm{SH}$ and SD were involved in study design, study procedure implementation, data analysis, and writing of the manuscript. TM reviewed the study design and interpreted the results. SH, SD, and TM participated in the study. All authors read and approved the final manuscript.

\section{Ethics approval and consent to participate}

This study was conducted according to the guidelines of the Declaration of Helsinki, and all procedures involving human subjects were approved by the ethics committee of National Hospital Organization Higashi-Hiroshima Medical Center (reference number: 28-59). We obtained verbal consent from each participant.

\section{Competing interests}

The authors declare that they have no competing interests.

\section{Publisher's Note}

Springer Nature remains neutral with regard to jurisdictional claims in published maps and institutional affiliations.

\section{Author details}

${ }^{1}$ Department of Nephrology, Hiroshima University Hospital, 1-2-3 Kasumi, Minami-ku, Hiroshima Zip 7348551, Japan. ${ }^{2}$ Department of Nephrology, National Hospital Organization Higashi-Hiroshima Medical Center, Hiroshima, Japan.

Received: 5 December 2017 Accepted: 7 May 2018

Published online: 06 June 2018

\section{References}

1. Higashihara E, Nutahara K, Kojima M, et al. Prevalence and renal prognosis of diagnosed autosomal dominant polycystic kidney disease in Japan. Nephron. 1998;80(4):421-7.

2. Grantham JJ. Clinical practice: autosomal dominant polycystic kidney disease. N Engl J Med. 2008;359(14):1477-85.

3. Grantham JJ, Chapman AB, Torres VE. Volume progression in autosomal dominant polycystic kidney disease: the major factor determining clinical outcomes. Clin J Am Soc Nephrol. 2006;1(1):148-57.

4. Gattone VH 2nd, Wang X, Harris PC, Torres VE. Inhibition of renal cystic disease development and progression by a vasopressin $\mathrm{V} 2$ receptor antagonist. Nat Med. 2003;9(10):1323-6.

5. Torres VE, Chapman AB, Devuyst $O$, et al. Tolvaptan in patients with autosomal dominant polycystic kidney disease. N Engl J Med. 2012; 367(25):2407-18.

6. Bhutani $H$, Smith V, Rahbari-Oskoui F, et al. A comparison of ultrasound and magnetic resonance imaging shows that kidney length predicts chronic kidney disease in autosomal dominant polycystic kidney disease. Kidney Int. 2015;88(1):146-51

7. Higashihara E, Nutahara K, Okegawa T, et al. Kidney volume and function in autosomal dominant polycystic kidney disease. Clinic Exp Nephrol. 2014; 18(1):157-65.

8. Irazabal MV, Rangel LJ, Bergstralh EJ, et al. Imaging classification of autosomal dominant polycystic kidney disease: a simple model for selecting patients for clinical trials. J Am Soc Nephrol. 2015;26(1):160-72.

9. Matsuo S, Imai E, Horio M, et al. Revised equations for estimated GFR from serum creatinine in Japan. Am J Kidney Dis. 2009;53(6):982-92.

10. Kidney Disease: Improving Global Outcomes (KDIGO) CKD Work Group. KDIGO 2012 clinical practice guideline for the evaluation and management of chronic kidney disease (modified for Japanese). Kidney Int Suppl. 2013; 3(1):1-150.

11. Hateboer N, v Dijk MA, Bogdanova N, et al. Comparison of phenotypes of polycystic kidney disease types 1 and 2. European PKD1-PKD2 Study Group. Lancet 1999; 353 (147):103-107. 
12. Torres VE, Higashihara $\mathrm{E}$, Devuyst $\mathrm{O}$, et al. Effect of tolvaptan in autosomal dominant polycystic kidney disease by CKD stage: results from the TEMPO 3:4 trial. Clin J Am Soc Nephrol. 2016;11(5):803-11.

13. Torres VE, Chapman AB, Devuyst O, et al. Multicenter, open-label, extension trial to evaluate the long-term efficacy and safety of early versus delayed treatment with tolvaptan in autosomal dominant polycystic kidney disease: the TEMPO 4:4 trial. Nephrol Dial Transplant. 2018;33(3):477-89.

14. Chapman AB, Bost JE, Torres VE, et al. Kidney volume and functional outcomes in autosomal dominant polycystic kidney disease. Clin J Am Soc Nephrol. 2012;7(3):479-86.

15. Boertien WE, Meijer E, de Jong PE, et al. Short-term effects of tolvaptan in individuals with autosomal dominant polycystic kidney disease at various levels of kidney function. Am J Kidney Dis. 2015;65(6):833-41.

16. Boertien WE, Meijer E, de Jong PE, et al. Short-term renal hemodynamic effects of tolvaptan in subjects with autosomal dominant polycystic kidney disease at various stages of chronic kidney disease. Kidney Int. 2013;84(6): 1278-86.

Ready to submit your research? Choose BMC and benefit from:

- fast, convenient online submission

- thorough peer review by experienced researchers in your field

- rapid publication on acceptance

- support for research data, including large and complex data types

- gold Open Access which fosters wider collaboration and increased citations

- maximum visibility for your research: over $100 \mathrm{M}$ website views per year

At BMC, research is always in progress.

Learn more biomedcentral.com/submissions 